\title{
EDUCAÇÃO PARA CONSERVAÇÃO DE ÁGUAS EM ESCOLAS PÚBLICAS: RELATO DE EXPERIÊNCIA EM PERNAMBUCO
}

\author{
Luiz Gustavo Costa Ferreira Nunes \\ Anna Elis Paz Soares \\ Juliana Karla da Silva \\ Fagner Fontes França \\ Simone Rosa da Silva
}

Resumo: Neste texto, relatamos uma experiência do grupo de extensão e pesquisa em recursos hídricos da Universidade de Pernambuco - AquaPOLI, no Projeto de Educação para Conservação de Águas em escolas públicas, desenvolvido na cidade do Recife, de agosto/2013 a dezembro/2015. O principal foco do projeto foi adisseminação do conhecimento científico e tecnológico dos recursos hídricos, através de atividades que permitiram a difusão de informações básicas e a conscientização da importância de ações de cada cidadão. Cerca de 1700 alunos foram contemplados pelo projeto. Os resultados demonstraram que a maioria dos alunos não sabe ou não compreende perfeitamente $o$ conceito "conservação de água", apenas uma pequena parcela (14\%) demonstrou ter consciência que a água potável do mundo possa vir a acabar. Por fim, mostrou-se evidente que o tema precisa ser melhor inserido no ensino público, sendo imprescindível que questões relacionadas com o uso da água, dentro e fora do ambiente escolar, sejam discutidas na escola.

Palavras chave: Extensão; Uso Racional da Água; Recursos Hídricos. Educação Infantil.

\begin{abstract}
In this paper, we report the experience of the extension and research in water resources' group ofthe University of Pernambuco - AquaPOLI, during an Education Project for Water Conservation in public schools, developed in Recife, from August/2013 to December/2015. The main focus of the project was the dissemination of scientific and technological knowledge of water sustainable management through activities that allowed the diffusion of important information and awareness of the importance of everyone's involvement. About 1700 students were involved in the program. The results showed that most students do not know or do not fully understand the concept of "water conservation", only a small portion (14\%) were aware that the world's drinking water could run out. Finally, it was evident that the theme needs to be better inserted in public education, and it is essential that issues related to the use of water inside and outside the school environment are discussed at school.
\end{abstract}

Keywords: Extension; Water Rational Use; Water resources; Child Education. 


\section{INTRODUÇÃO}

A Declaração Universal dos Direitos da Água, elaborada pela ONU em 1992, afirma que o equilíbrio e o futuro do nosso planeta dependem da preservação da água, não devendo esta ser desperdiçada ou utilizada de forma inconsciente para que não se chegue a uma situação de esgotamento. O crescimento populacional, dos níveis de urbanização e industrialização, bem como o aumento na produção e consumo vem aumentando cada vez mais a demanda por água potável. Esta, por sua vez, está em escassez em diversos países devido, principalmente, à má governança, poluição, fatores climáticos e desperdício. Caso este desequilíbrio entre a oferta e demanda de água potável não seja minimizado, haverá um aumento severo na crise hídrica mundial (UNESCO, 2015).

Assim, chegamos ao conceito de conservação de água que é um conjunto de atividades, medidas e estímulos que têm como principais objetivos: a redução da demanda, perdas e desperdício de água; a melhoria da sua utilização; a implantação de métodos e tecnologias para sua economia; além da informação e conscientização dos usuários (TOMAZ, 2001; ANA/FIESP/SINDUSCON, 2005; MMA, 2014). Entendendo-se, assim, que conservação de água deve envolver todos os aspectos que interfiram no volume de água destinado às atividades humanas, em especial, ao consumo humano (COELHO, 2007).

No Brasil, as principais ações federais direcionadas ao uso racional da água foram lançadas pelo Ministério do Planejamento: o Programa Nacional de Combate ao Desperdício de Água (1997) e o Programa Brasileiro de Qualidade e Produtividade da Construção Habitacional (MPO/SEPURB), em 1998. Além disso, Programas de Uso Racional da Água (PURA) foram desenvolvidos em diferentes tipologias de edifícios, a exemplo da Universidade de São Paulo - USP, que desenvolveu um amplo programa de redução de perdas em seu campus e, durante o período de 1998 a 2002, reduziu em torno de $39 \%$ o consumo de água potável em sete unidades, com a implantação de medidas físicas e educativas(GONÇALVES et al., 2005).

Em Pernambuco, a Lei $\mathrm{N}^{\circ}$ 14.572/2011 objetiva a promoção de medidas necessárias à conservação, à redução do desperdício e à utilização de fontes alternativas para a captação e o aproveitamento da água nas edificações, bem como a conscientização dos usuários sobre a sua importância para a vida. A referida norma enfatiza, em seu artigo $10^{\circ}$, que "os sistemas hidráulico e sanitário das novas edificações serão projetados de modo a propiciar a economia 
e o combate ao desperdício de água, privilegiando a sustentabilidade dos recursos hídricos, sem prejuízo do conforto e da segurança dos habitantes". (PERNAMBUCO, 2011).

Sintonizado com a necessidade de adotar medidas sustentáveis em edificações, o Estado de Pernambuco aprovou o Decreto $N^{o} 40.903$, de 18 de julho de 2014, que dispõe sobre a gestão e a racionalização do consumo de água no âmbito do Poder Executivo Estadual e de suas entidades vinculadas. A referida norma cria o cargo de Gestor de Água nos órgãos e entidades integrantes do Poder Público Estadual, que é responsável pelo gerenciamento e controle do consumo de água e, ainda, por propor e identificar ações para racionalização das despesas com água e saneamento. Também determina que os imóveis construídos com recursos públicos devem ter dispositivos hidráulicos para redução do consumo de água, especificando os equipamentos hidráulicos poupadores (PERNAMBUCO, 2014).

Ywashima (2005) e Nunes et al. (2018) evidenciam que em muitos casos, a redução de consumo não depende apenas da instalação e eficiência dos equipamentos com tecnologia economizadora, mas também do comportamento dos usuários. Sendo assim, a academia tem um importante papel a desempenhar nesse tema, seja através da pesquisa de novas tecnologias, do desenvolvimento de Programas do Uso Racional da Água ou da participação na conscientização da sociedade para o papel de cada cidadão na conservação da água.

A responsabilidade da sociedade pelos recursos hídricos, cada vez mais ameaçados devido aos impactos ambientais, desperta para a necessidade do uso racional da água, que está diretamente relacionado com o comportamento dos usuários na realização das atividades que envolvem o emprego desse insumo. Sendo assim, mesmo com o emprego de tecnologias sofisticadas nos pontos de consumo, sem a devida sensibilização dos envolvidos, pode conduzir a resultados modestos quando comparados à situação em que os usuários possuem uma postura economizadora.

Conforme Ribeiro (2011), a universidade há uma responsabilidade social, um compromisso em estabelecer um diálogo dinâmico entre a instituição e a sociedade, assumindo uma postura construtivista, construindo e reconstruindo o conhecimento, de modo que seja possível dar respostas à sociedade quanto às questões próprias do seu tempo.

Neste contexto, o projeto objetivou, através de palestras e atividades pedagógicas, contribuir com a disseminação do conhecimento científico e tecnológico dos recursos hídricos, desenvolvendo atividades que permitam não só a difusão de informações básicas, como também a conscientização do público a respeito da importância da participação de cada

Revista Extensão em Foco, nº 20, Jan./Jul. (2020), p. 102 - 114. 
cidadão na preservação dos recursos naturais. Os professores e alunos das escolas da rede pública, do ensino fundamental, do ensino médio e da Educação de Jovens e Adultos (EJA) foram o público-alvo, uma vez que usualmente são os menos favorecidos com atividades educativas diversificadas.

\section{METODOLOGIA}

As atividades de extensão do projeto foram desenvolvidas em três etapas distintas, aliadas às atividades de pesquisa, e ambas executadas por uma equipe de quatro alunos de graduação em engenharia civil,sendo três voluntários e um bolsista, sob a orientação da Coordenação do Grupo de Pesquisa, Extensão e Ensino em Recursos Hídricos da Universidade de Pernambuco - AquaPOLI. Inicialmente, o grupo estabeleceu um primeiro contato com a Secretaria de Educação do Estado de Pernambuco (SEE-PE), a fim de ser direcionado para escolas que pudessem se tornar parceiras do projeto.

$\mathrm{Na}$ primeira etapa, foi realizado um contato inicial com as escolas, a fim de agendar as visitas para realização de cadastro preliminar. O cadastro consistiu no diagnóstico das instalações hidrossanitárias, registro fotográfico, coleta de dados referentes ao número de funcionários, horário de funcionamento, pontos de consumo de água, registro mensal de volume de água consumido, gastos com água na escola, hábitos de consumo de água, demandas hídricas potáveis e não potáveis da instituição. Além disso, foi observada a receptividade da escola em participardo projeto e sua proximidade geográfica com a universidade.

$\mathrm{Na}$ segunda etapa, objetivou-se atender a uma demanda existente das escolas sobre informações gerais de recursos hídricos, que pôde ser atendida através de visitas dos monitores do projeto às escolas, ministrando palestras adequadas a cada público sobre a temática da água. Também foidistribuído em todas as escolas material informativo e educativo (folders, cartilhas,cartazes) para auxiliar na conscientização de todos os usuários (alunos, professores e funcionários) para o uso racional da água. Como atividades complementares,foram sugeridas visitas guiadas ao Espaço Ciência (EC) e Estação de Tratamento de Água. O Espaço Ciência é um museu a céu aberto e conta em sua programação com diversas oficinas práticas voltadas ao tema água.

Revista Extensão em Foco, nº 20, Jan./Jul. (2020), p. 102 - 114. 
A disseminação do conhecimento técnico e científico dos recursos hídricos buscou trazer informações básicas para conscientizar os alunos e professores sobre a importância das ações de cada cidadão, acreditando que os mesmos agirão como multiplicadores, replicando os conhecimentos adquiridos em suas casas e na comunidade.

As palestras contemplaram os seguintes assuntos: a água no planeta, estados físicos da água, ciclo hidrológico, como a água chega até as residências, sistema de abastecimento de água, consumo de água, disponibilidade hídrica e medidas para uso racional da água. Especificamente, a palestra do ensino médio ainda abordava outros assuntos, tais como: múltiplos usos da água e outorga de uso de água, além de trazer questões do ENEM (Exame Nacional do Ensino Médio) sobre o tema, visando estimular ainda mais esse público específico.

Além das palestras voltadas para os alunos, os itens foram apresentados aos professores, alertando-os sobre a interdisciplinaridade do tema, e guiando-os para a consonância com o projeto de pesquisa, dando diversas sugestões de atividades acadêmicas e pedagógicas a serem trabalhadasem sala de aula.

Em 2015, a equipe elaborou um questionário sucinto para avaliar o nível de conhecimento prévio dos alunos sobre o tema, com questões dicotômicas (cujas respostas eram SIM ou NÃO) e discursivas. O questionário abordou os seguintes tópicos: o que é conservação de água, métodos ou técnicas que possam ser utilizados para reduzir o consumo de água potável e opinião do aluno sobre a finitude da água potável (Figura 1). As respostas das questões discursivasestavam condicionadas a resposta SIM das questões dicotômicas e foram analisadas e categorizadas pelos autores em: DC - desempenho construído, quando o aluno demonstra o desempenho esperado; DEC - desempenho em construção, quando ainda se encontra no processo de elaboração conceitual; e DNC - desempenho não construído, quando não demonstra nenhum indício de desempenho definido.

Figura 1- Questionário aplicado aos alunos em 2015.

Revista Extensão em Foco, nº 20, Jan./Jul. (2020), p. 102 - 114. 


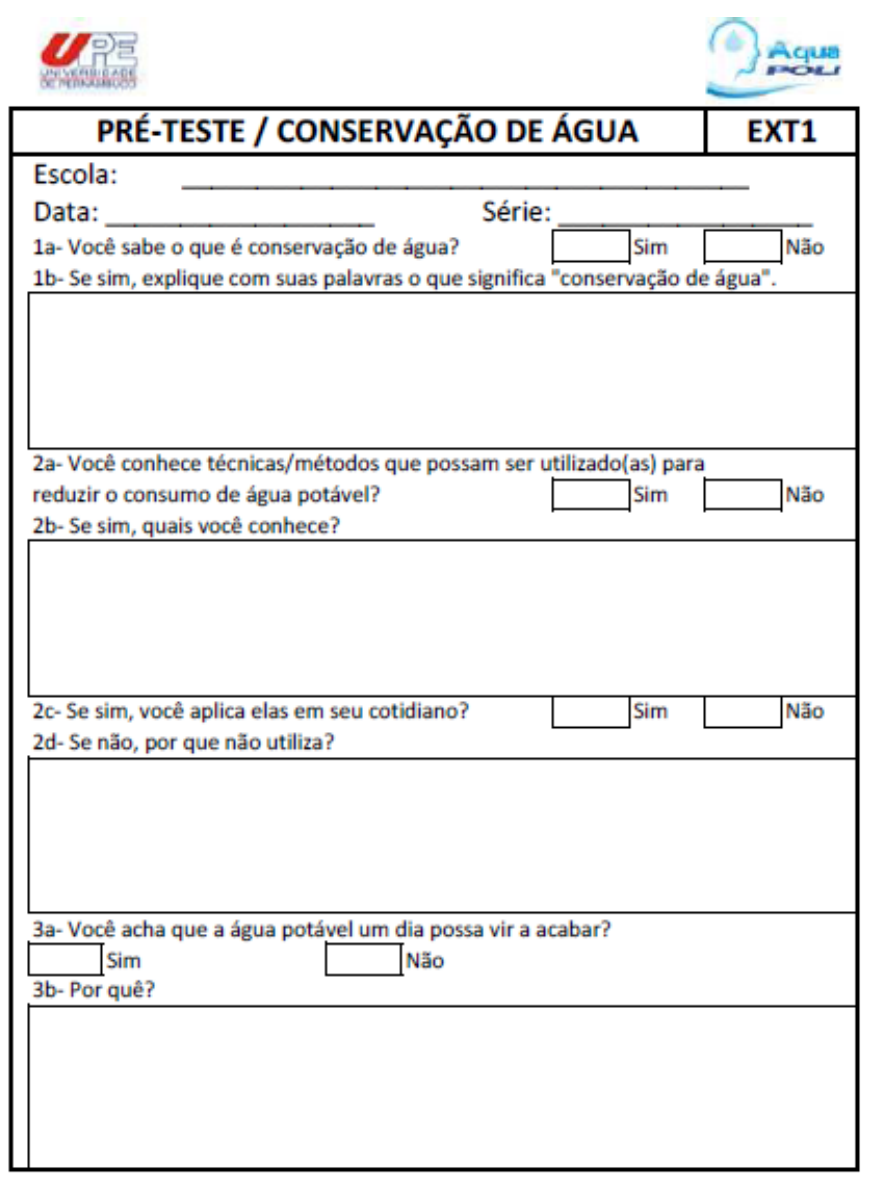

A terceira etapa consistiu em uma autoavaliação por parte dos envolvidosno projeto, através da leitura da sua participação, desenvolvida em reuniões periódicas da equipe para verificar os pontos positivos e negativos da experiência nas atividades extensionistas.

\section{RESULTADOS}

No ano de 2013, foram realizadas quatro palestras para 207 alunos de uma escola pública de Recife. As Tabelas 1 e 2 apresentam o público atingido diretamente pelas ações extensionistas da equipe do AquaPOLI no período de abrangência do projeto.

Tabela 1- Quantitativo de escolas, palestras e alunos contemplados

\section{Palestras}

Revista Extensão em Foco, no 20, Jan./Jul. (2020), p. 102 - 114. 


\begin{tabular}{|c|c|c|c|}
\hline Ano & Escolas Atendidas & Palestras & Alunos \\
\hline $\mathbf{2 0 1 3}$ & 1 & 4 & 207 \\
\hline $\mathbf{2 0 1 4}$ & 5 & 17 & 917 \\
\hline $\mathbf{2 0 1 5}$ & 2 & 4 & 174 \\
\hline Total & $\mathbf{8}$ & $\mathbf{2 5}$ & $\mathbf{1 2 9 8}$ \\
\hline
\end{tabular}

Tabela 2 - Quantitativo de escolas e alunos contemplados pelas visitas guiadas no Espaço Ciência

\begin{tabular}{|c|c|c|}
\hline \multicolumn{3}{|c|}{ Visitas Guiadas } \\
\hline Ano & Escolas Atendidas & Alunos \\
\hline $\mathbf{2 0 1 4}$ & 1 & 95 \\
\hline $\mathbf{2 0 1 5}$ & 1 & 303 \\
\hline Total & $\mathbf{2}$ & $\mathbf{3 9 8}$ \\
\hline
\end{tabular}

Em 2014, a equipe recebeu uma lista da Secretaria de Educação do Estado com algumas escolas situadas no entorno da Escola Politécnica de Pernambuco, visitando um total de oito instituições. Destas, duas escolas foram selecionadas para desenvolver o projeto de pesquisa, que consistiu em monitorar o consumo de água potável e realizar campanhas educativas. Portanto, neste ano, as atividades ficaram mais concentradas nestas duas escolas, onde foram realizadas 15 palestras para um total de 873 alunos. Também foram realizadas duas palestras para os professores, totalizando 34 participantes.

Além das escolas visitadas e selecionadas para o projeto piloto de pesquisa, o grupo também foi procurado por três outras instituições de ensino. Uma delas solicitou auxilio para uma visita guiada ao Espaço Ciência, acompanhando 95 alunos. Nas outras duas escolas, foram ministradas palestras para 20 e 24 alunos, respectivamente.

No ano seguinte (2015), a equipe continuou atendendo às solicitações de escolas e realizou palestras em duas instituições, totalizando174 alunos. Uma delas também recebeu auxílio na visita guiada ao Espaço Ciências, na qualcompareceram 303 alunos.

Nos dois anos e meio de projeto, foram ministradas 25 palestras para 1298 alunos de escolas públicas, assim como visitas guiadas para 398 alunos. Sendo este um projeto pioneiro na Universidade de Pernambuco, o número de contemplados foi considerado satisfatório.

Revista Extensão em Foco, no 20, Jan./Jul. (2020), p. 102 - 114. 
No ano de 2015, de forma concomitante às palestras, foram aplicados questionários aos 174 alunos de duas escolas distintas, antes da exposição do conteúdo, conforme Tabela 01. Ao marcarem "sim" às perguntas, os alunos tinham que justificar suas repostas por escrito. A partir da análise dessas respostas, foram atribuídos os conceitos de desempenho definidos na metodologia. As Figuras 2, 3, 4 e 5 sintetizam os resultados obtidos com a aplicação dos questionários.

Figura 2- O que é conservação de água?

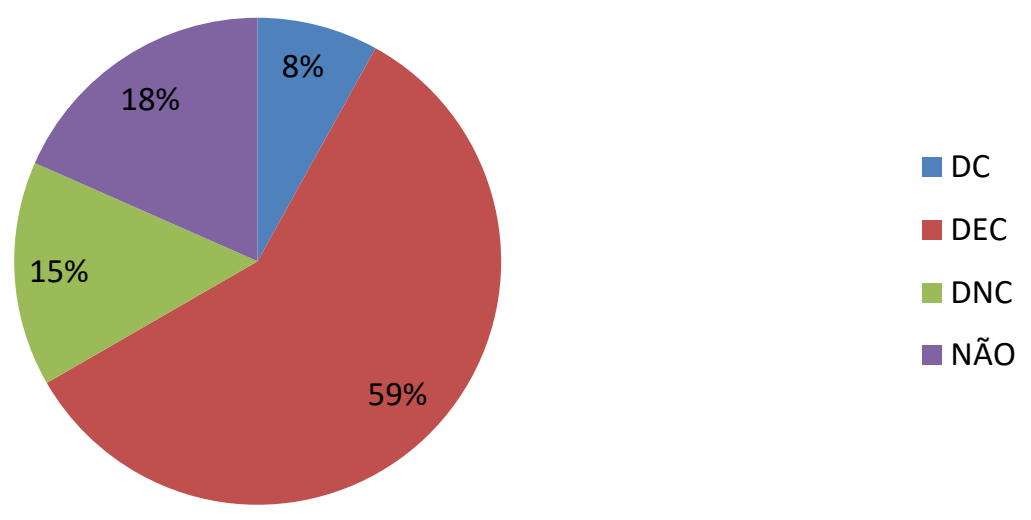

Legenda: DC - desempenho Construído; DEC - desempenho em Construção; DNC desempenho não construído.

Figura 3- Você conhece técnicas/métodos que possam reduzir o consumo de água potável?

Revista Extensão em Foco, nº 20, Jan./Jul. (2020), p. 102 - 114. 


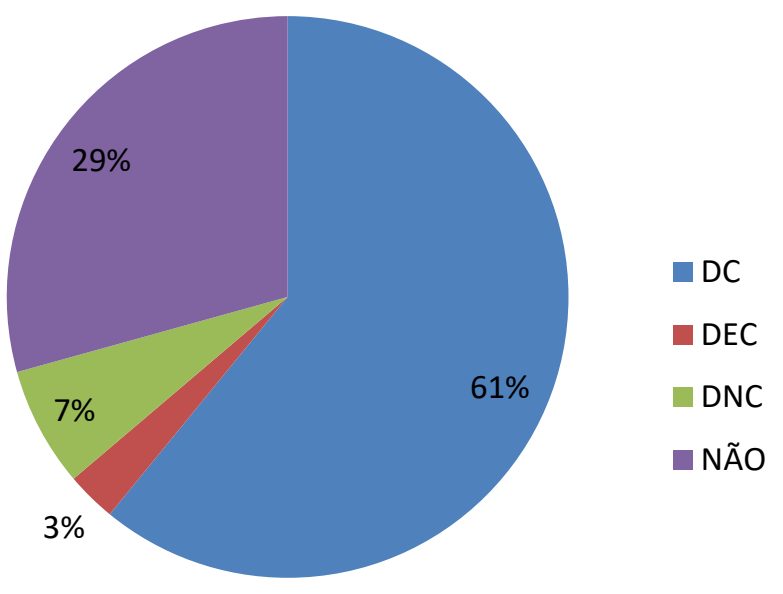

Legenda: DC - desempenho Construído; DEC - desempenho em Construção; DNC desempenho não construído.

Figura 4- Você utiliza essas(es) técnicas/métodos no dia a dia?

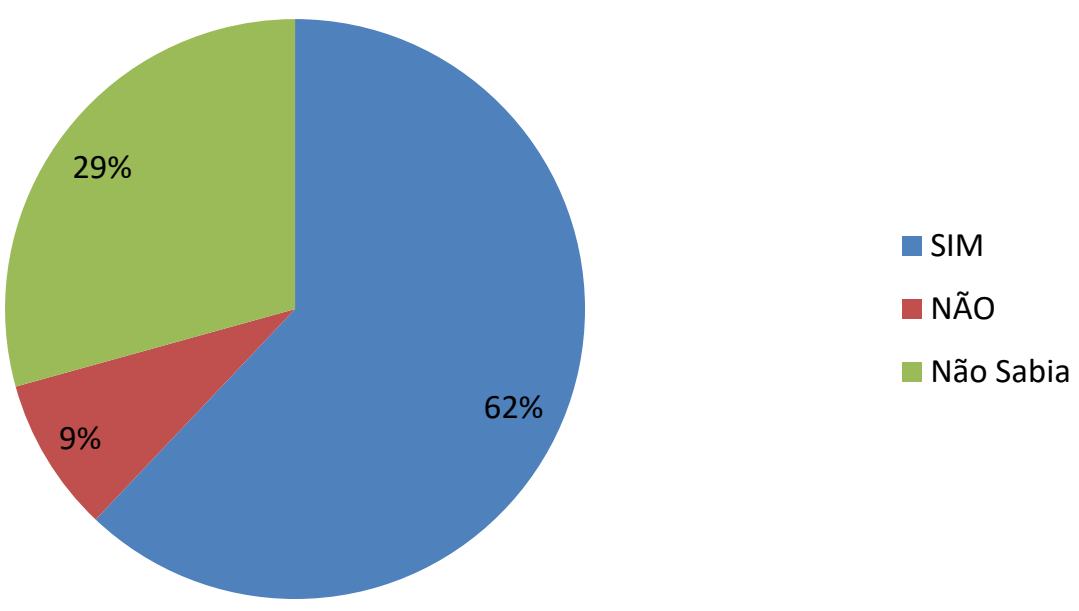

Legenda: DC - desempenho Construído; DEC - desempenho em Construção; DNC desempenho não construído.

Figura 5- Você acha que a água potável um dia possa vir a acabar?

Revista Extensão em Foco, no 20, Jan./Jul. (2020), p. 102 - 114. 


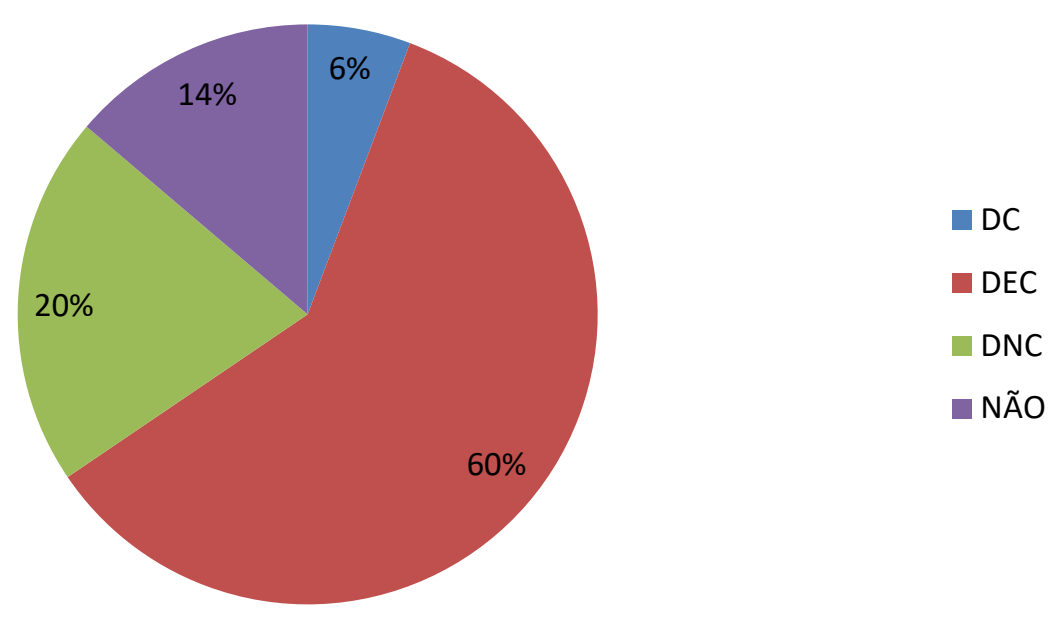

Legenda: DC - desempenho Construído; DEC - desempenho em Construção; DNC desempenho não construído.

A Figura 2 mostra que os alunos não sabem (18\%) ou não compreendem perfeitamente (74\%)o termo “conservação de água". Porém, aFigura 3 mostra que $61 \%$ dos alunos conhecem métodos para reduzir o consumo de água. Por sua vez, aFigura 4 apresenta que $62 \%$ aplicam, diariamente, métodos para diminuir o consumo de água, demonstrando que os alunos, mesmo não tendo o conhecimento construído, já realizam algumas práticas no sentido de conservação dos recursos hídricos. Ademais, a Figura 5 traz um resultado alarmante: muitos não possuem o conhecimento completo (apenas, 6\%) de que a água potável do mundo pode vir a acabar e que, para evitar essa situação, é preciso agir de imediato. Além disso, $14 \%$ não acredita que isso possa vir a ocorrer.

Embora a dimensão da amostra seja pequena em relação ao universo, as Figuras 2, 3, 4 e 5 mostram que, provavelmente, há uma deficiência no ensino das escolas estudadas para a conscientização do corpo discente quanto à importância do papel do cidadão na conservação dos recursos naturais, em especial, dos recursos hídricos. De um modo geral, os alunos apresentaram um desempenho em construção, aplicando ações de conservação de água em seu dia a dia sem compreender a necessidade e a importância dessas ações.

Outrossim, a interação com as escolas permitiu identificar uma dificuldade em trazer a temática da água para dentro das instituições através de palestras. Em algumas ocasiões, alunos e professores não demonstraram interesse em participar das atividades e dar 
continuidade ao processo de conscientização para o uso racional da água. Esses problemas contribuíram para um redirecionamento das atividades extensionistas do grupo.

\section{DISCUSSÕES}

Observou-se dificuldade em envolver mais alunos da universidade devido a pouca empatia por parte de estudantes universitários de engenharia civil com a temática dos recursos hídricos. Além disso, não há um incentivo para o engajamento em causas sociais. Tais fatores influenciaram na continuidade do projeto e das atividades extensionistas do grupo.

Outro ponto perceptível para equipe foi afalta de interesse de parte do corpo docente das escolas, demonstrando pouca empatia em dar continuidade ao trabalho de disseminação do conteúdo apresentado no dia a dia da sala de aula. Este fato pode ser ocasionado pela necessidade de cumprimento ao calendário escolar e pela falta de estímulo à interdisciplinaridade.

Ademais, verifica-se que há pouco engajamento/envolvimento por parte da comunidade escolar, dirigentes, sociedade civil no fomento do tema "conservação de água", que poderia ser trabalhado de maneira interdisciplinar.

\section{CONCLUSÕES}

Através dos questionários aplicados, pode-se perceber que o ensino público carece de melhoriasna sua função de gerar cidadãos conscientes para a conservação dos recursos hídricos e para a formação de um mundo mais sustentável. Para tanto, é imprescindível que questões relacionadas com o usoda água, dentro e fora do ambiente escolar, sejam mais discutidas na escola.

Ressalta-se a interdisciplinaridade do tema água, que pode ser trabalhado em todas as esferas como, por exemplo: matemática e suas tecnologias, associando-o à medição de volumes, leitura de hidrômetros e interpretação das informações contidas na conta de água; ciências da natureza, observando os aspectos físicos e químicos da água; ciências humanas, em que poderia ser trabalhado o desenvolvimento das cidades atrelado à disponibilidade de água e os conflitos atuais por esse recurso; linguagem, códigos e suas tecnologias, através do trabalho de textos com a temática. Este estímulo interdisciplinar poderia melhorar o 
engajamento do corpo discente e dos demais atores dentro ambiente escolar no âmbito da conservação de água.

No que diz respeito aos resultados para a universidade, como contribuição para o crescimento da equipe, este projeto colaborou para a percepção da indissociabilidade entre ensino, pesquisa e extensão para o estudante universitário, que deixou de ser um mero receptáculo de um conhecimento, e tornou-se parte do processo, no qual ele também foi o tutor (apoiando o crescimento possibilitado pelo conhecimento), o pedagogo (conduzindo o processo de conhecimento), e o orientador (aquele que aponta a direção do conhecimento), permitindo, assim, reconhecer-se como agente de garantia de direitos e deveres, além de transformação social.

\section{Referências}

ANA/FIESP/SINDUSCON(SP). Conservação e reúso da água em edificações. São Paulo: Prol Editora Gráfica, 2005. 151 p.

COELHO, A. C.Medição de água individualizada - Manual de Consulta. Recife, PE: Ed. do Autor. 2007, 202 p.

GONÇALVES, O. M.et al. Indicadores de Uso Racional da Água para Escolas de Ensino Fundamental e Médio. Ambiente Construído, Porto Alegre, v. 5, n. 3, p. 63, jul./set. 2005.

MINISTÉRIO DO MEIO AMBIENTE - MMA. Secretaria de Articulação Institucional e Cidadania Ambiental. Manual Prático para uso e conservação da água em prédios públicos. Brasília, 2014. 83p.

NUNES, L. G. C. F. Plano de conservação de água: escolas públicas estaduais da cidade do Recife. 2018. 154f. Dissertação de Mestrado em Engenharia Civil. Escola Politécnica da Universidade de Pernambuco. Recife, PE. 2018.

PERNAMBUCO. Lei $\mathbf{N}^{\mathbf{o}}$ 14.572/2011. Estabelece normas para o uso racional e reaproveitamento das águas nas edificações do Estado de Pernambuco. Recife, 2011.

PERNAMBUCO. Decreto $\mathbf{N}^{\mathbf{0}} \mathbf{4 0 . 9 0 3 / 2 0 1 4}$. Dispõe sobre a gestão e a racionalização do consumo de água no âmbito do Poder Executivo Estadual e de suas entidades vinculadas. Recife, 2014.

RIBEIRO, R. M. da C. A extensão universitária como indicativo de responsabilidade social. Revista Dialogos: pesquisa em extensão universitária, Brasília, v.15, n.1, jul, 2011

TOMAZ, P. Economia de água para empresas e residências. Um estudo atualizado sobre o uso racional da água. São Paulo: Navegar Editora, 2001.

Revista Extensão em Foco, no 20, Jan./Jul. (2020), p. 102 - 114. 
USP. Programa de Uso Racional da Água da Universidade de São Paulo - PURA. Acesso em: 03 out 2009. Disponível em: http://www.pura.poli.usp.br

YWASHIMA, L. 2005.Avaliação do uso da água em edifícios escolares públicos e análise de viabilidade econômica da instalação de tecnologias economizadoras nos pontos de consumo. Dissertação de Mestrado em Engenharia Civil. Universidade Estatual de Campinas. Campinas, SP.

UNESCO (United Nations Educational, Scientific and Cultural Organization). The United Nations World Water Development Report 2015: Water for a Sustainable World. Paris, UNESCO. 2015.

Revista Extensão em Foco, nº 20, Jan./Jul. (2020), p. 102 - 114. 